\title{
Synthesis and Application of Layered Double Hydroxide for the removal of Copper in Wastewater
}

\author{
Ayawei N. ${ }^{1}$, Ekubo A. T. ${ }^{2}$, Wankasi D. ${ }^{1,3}$, \& Dikio E. D. ${ }^{1,3}$ \\ ${ }^{1}$ Department of Chemical Sciences, Niger Delta University, Wilberforce Island, Bayelsa State, Nigeria \\ ${ }^{2}$ Department of Chemical Sciences, Federal University of Technology, Otuoke, Bayelsa State, Nigeria \\ ${ }^{3}$ Applied Chemistry and Nanoscience Laboratory, Department of Chemistry, Vaal University of Technology, P. \\ O. Box X021, Vanderbijlpark, South Africa
}

Correspondence: Ayawei N., Department of Chemical Sciences, Niger Delta University, Wilberforce Island, Bayelsa State, Nigeria. E-mail: ayawei4acad@gmail.com

\author{
Received: February 17, 2015 Accepted: March 3, 2015 Online Published: March 24, 2015 \\ doi:10.5539/ijc.v7n1p122 URL: http://dx.doi.org/10.5539/ijc.v7n1p122
}

\begin{abstract}
Ni-Al Layered double hydroxide (Ni-Al LDHs) with $\mathrm{M}^{2+}: \mathrm{M}^{3+}$ (4:1) ratio was synthesized by co-precipitation method from nitrate salt solutions. The layered double hydroxide was characterized by Fourier transform infrared spectroscopy, X-Ray Diffraction, Energy Dispersive Spectroscopy/Scanning Electronic Microscopy. The influences of phase contact time, temperature and initial concentrations were investigated to optimize the conditions for maximum adsorption. The experimental data were analyzed by Langmuir and Freundlich isotherm models and fitted well with correlation coefficient values of 0.9996 and 0.9995 respectively. The thermodynamic parameters of Isosteric heat of adsorption $\left(\Delta \mathrm{H}_{\mathrm{x}}\right)$, Activation energy $\left(\mathrm{E}_{\mathrm{a}}\right)$, Enthalpy change $\left(\Delta \mathrm{H}^{\mathrm{o}}\right)$ and Entropy change $\left(\Delta S^{\circ}\right)$ were calculated to be $18.1 \mathrm{KJ} / \mathrm{mol}, 1.447 \mathrm{KJ} / \mathrm{mol},-7.135 \mathrm{~J} / \mathrm{mol}$ and $24 \mathrm{~J} / \mathrm{molK}$ respectively. The results shows that the adsorption process was spontaneous and exothermic.
\end{abstract}

Keywords: synthesis, characterization, adsorption isotherms, thermodynamics

\section{Introduction}

Layered double hydroxide (LDH) is a class of anionic clays with high anion exchange capacities which can be used as an effective adsorbent for the removal of variety of anionic pollutants. The chemical composition of LDHs can be described by the general formula $\left[\mathrm{M}^{2+}{ }_{1-x} \mathrm{M}^{3+}{ }_{x-}(\mathrm{OH})_{2}\right]^{x^{+}}\left[\left(\mathrm{A}^{n-}\right)_{x_{n}} \cdot \mathrm{mH}_{2} \mathrm{O}\right]^{x^{-}}$where $\mathrm{M}^{2+}=$ divalent metals, $\mathrm{M}^{3+}$ is trivalent metals, and $\mathrm{A}^{n^{-}}$is an anion with charge $n$. Molar fraction number mol of water in LDH interlayer per formula weight of compounds and $x=\mathrm{M}^{3+} /\left(\mathrm{M}^{3+}+\mathrm{M}^{2+}\right)$ molar fraction (normally, it is between 0.2 and 0.33 ) (F. Cavani, et al, 1991). The most common method for the synthesis of LDHs is co-precipitation. However, other synthesis methods such as rehydration, hydrothermal reaction, pre-pillaring and intercalation have been reported (Hetterley, R. D. et al, 2008, Richardson, M. C. et al, 2009). The flexibility of layered double hydroxides has place premium on their applications in various fields including catalysis, photochemistry, pharmacy, adsorption etc. The use of layered double hydroxide for the removal of heavy metals in aqueous media has been studied and the results shows the adsorption capacities of LDHs (G. N. Pshinko, 2013, Gong, J. et al 2001, M. R. Perez, et al, 2006, Zaini, et al, 2011). However, in all these studies, calcination has been further done to the original LDH either to enhance the quality of crystals or increase the adsorption capacity which ultimately makes the process more expensive.

The presence of heavy metals in our environment is a cause of great concern to environmentalists and Governments all over the world because of their effects on humans, plants and animals. As reported by Mahvi, $\mathrm{H}$. A., 2008, heavy metal ions in aqueous solutions creates many problems for humans, animals and plants. Copper is very essential to human life and health, but is also very dangerous at higher levels of concentration. Copper is extensively discharged from the electrical industry, pulp, paper mills and petroleum refineries (Igwe, J. C. et al 2006). A number of technologies for the removal of heavy metal ions from aqueous solutions have been developed over the years (Gupta, V. K. et al 2006, Lu, H. J. et al 2008). The most important of these techniques include chemical precipitation, filtration and reverse osmosis. However, all these techniques have their inherent advantages and limitations in application. Adsorption has become one of the preferred methods for removal of 
toxic contaminants from water as it has been found to be very effective, economical, versatile and simple (King, P., et al, 2006, Chen, D. Z. et al, 2010). Adsorption has the additional advantages of applicability at very low concentrations, suitability for using batch processes, ease of operation, little sludge generation and low capital cost (Tran, H. H. et al, 1999, Mohanty, K., 2006). The main properties of the adsorbents are strong affinity and high loading capacity for the removal of heavy metals.

This paper takes a look at the direct application of the LDH produced by coprecipitation method for the adsorption of copper ions. The thermodynamic and equilibrium parameters were determined for optimization and design purpose.

\section{Materials and Methods}

\subsection{Synthesis of $L D H$}

Carbonate form of $\mathrm{Ni}-\mathrm{Al} \mathrm{LDH}$ was synthesized by co-precipitation method. A $50 \mathrm{ml}$ aqueous solution containing $0.3 \mathrm{M} \mathrm{Ni}\left(\mathrm{NO}_{3}\right)_{2} \cdot 6 \mathrm{H}_{2} \mathrm{O}$ and $0.1 \mathrm{M} \mathrm{Al}\left(\mathrm{NO}_{3}\right)_{3} .9 \mathrm{H}_{2} \mathrm{O}$ with $\mathrm{Ni} / \mathrm{Al}$ ratios $4: 1$, was added drop wise into a $50 \mathrm{ml}$ mixed solution of $\left(\mathrm{NaOH}(2 \mathrm{M})+\mathrm{Na}_{2} \mathrm{CO}_{3}(1 \mathrm{M})\right.$ with vigorous stirring and maintaining a $\mathrm{pH}$ of greater than 10 at room temperature. After complete addition which last between 2 hours 30 minutes to 3 hours, the slurry formed was aged at $60^{\circ} \mathrm{C}$ for 18 hours. The product was centrifuged at $5000 \mathrm{rpm}$ for 5 minutes with distilled water (3-4 times) and dried by freeze drying.

\subsection{Characterization of Layered Double Hydroxide}

The morphology and microstructure of the sample were characterized by a Scanning Electron Microscopy (SEM) (type FEI Quanta 200), X-ray diffraction (XRD, Bruker D8 diffractometer with $\mathrm{Cu}$ K $\alpha$ radiation, $\lambda=1.5418 \AA$, a scan rate of $0.02^{\circ} 2 \theta / \mathrm{s}$ from 5 to $70^{\circ}$ ) and Fourier transformation infrared spectra (FT-IR, Perkin-Elmer-283B FT-IR spectrometer, the wave number range from 400 to $4000 \mathrm{~cm}^{-1}$ ).

\subsection{Aqueous Solution of Heavy Metal}

All reagents used for this study were analytical reagent grade and were procured from Zayo-Sigma chemical Ltd. Jos, Nigeria. $1000 \mathrm{mg} / \mathrm{l}$ aqueous solutions of the metals ion was prepared as stock from their salts $(\mathrm{CuSO} 4)$. From the stock, working solutions of $0.08 \mathrm{~g} / \mathrm{LCu}, 0.12 \mathrm{~g} / \mathrm{LCu}$ and $0.16 \mathrm{~g} / \mathrm{LCu}$ were prepared from appropriate aliquots diluted to the appropriate concentration. The total concentration of each metal ion in the aqueous solution was confirmed by analysis using (Unicam thermo/solar system 2009 model) Atomic Adsorption Spectrometer (AAS).

\subsection{Adsorption Experiments}

Batch adsorption experiments were carried out to investigate the quantitative uptake of copper by the layered double hydroxide. The analytical variables such as time, temperature, and copper initial concentration have been studied in detail for batch technique with $0.2 \mathrm{~g}$ of the adsorbent.

The adsorption experiments were performed at three different temperatures viz. 40,60 and $80^{\circ} \mathrm{C}$ in a thermostat attached with a shaker, Remi make. The constancy of the temperature was maintained with an accuracy of \pm $0.5^{\circ} \mathrm{C}$.

In order to determine the rate of adsorption, experiments were conducted with different initial concentrations of copper $(0.08 \mathrm{~g} / \mathrm{l}, 0.12 \mathrm{~g} / \mathrm{l}$ and $0.16 \mathrm{~g} / \mathrm{l})$. All other factors were kept constant.

\subsection{Data Analysis}

The metal adsorption $\left(\mathrm{q}_{\mathrm{e}}\right)$ and the removal efficiency $\mathrm{R}$ of the layered double hydroxide were calculated by the following equations (Mohanty, K., 2006, Zhang, L. et al, 1998).

$$
\begin{aligned}
& q_{e}=\frac{v}{M}\left(C_{o}-C_{e}\right) \\
& R(\%)=\frac{C_{o}-C_{e}}{C_{o}} \times 100
\end{aligned}
$$

with $\mathrm{q}_{\mathrm{e}}$ as metal uptake capacity ( $\mathrm{mg} / \mathrm{g}$ double layered hydroxide at equilibrium), $\mathrm{C}_{\mathrm{e}}$ is metal ion concentration in solution $(\mathrm{mg} / \mathrm{l})$ at equilibrium, $\mathrm{C}_{\mathrm{o}}$, the initial metal ion solution $(\mathrm{mg} / \mathrm{l}), \mathrm{V}$, the volume of solution in litres and $\mathrm{M}$, the dry weight of layered double hydroxide used in $(\mathrm{g})$.

Langmuir plot was carried out using the linearized equation 3 below: 


$$
\frac{M}{x}=\frac{1}{a b C_{e}}+\frac{1}{b}
$$

Where $\mathrm{X}$ is the amount of $\mathrm{Cu}^{2+}$ adsorbed per mass $\mathrm{M}$ of double layered hydroxide in $\mathrm{mg} / \mathrm{g}$, $\mathrm{a}$ and $\mathrm{b}$ are the Langmuir constants obtained from the slope and intercepts of the plots.

The essential characteristics of the Langmuir isotherm were expressed in terms of a dimensionless separation factor or equilibrium parameter $S_{f}$.

$$
S_{f}=\frac{1}{1+a C_{o}}
$$

With $\mathrm{C}_{\mathrm{o}}$ as initial concentration of $\mathrm{Cu}^{2+}$ in solution, the magnitude of the parameter $\mathrm{S}_{\mathrm{f}}$ provides a measure of the type of adsorption isotherm. If $\mathrm{S}_{\mathrm{f}}>1.0$, the isotherm

is unfavourable; $\mathrm{S}_{\mathrm{f}}=1.0$ (linear); $0<\mathrm{S}_{\mathrm{f}}<1.0$ (favourable) and $\mathrm{S}_{\mathrm{f}}=0$ (irreversible).

The adsorption intensity of the $\mathrm{Cu}^{2+}$ in the Layered double hydroxide was assessed from the Freundlich plot using the linearized equation 5 below

$$
\operatorname{In} \frac{x}{m}=\frac{1}{n}\left(\operatorname{In} C_{e}\right)+\operatorname{In} K
$$

where $\mathrm{K}$ and $\mathrm{n}$ are Freundlich constants and $1 / \mathrm{n}$ is approximately equal to the adsorption capacity.

The fraction of double layered hydroxide surface covered by the $\mathrm{Cu}^{2+}$ was computed using equation 6 :

$$
\theta=1-\frac{\mathrm{C}_{\mathrm{e}}}{\mathrm{C}_{\mathrm{o}}}
$$

With $\theta$ as degree of surface coverage

The effectiveness of the adsorbent (double layered hydroxide) was assessed by the number of cycles of equilibrium sorption process required to reduce the levels of $\mathrm{Cu}^{2+}$ in solution according to the value of the distribution (partition coefficient $\left(\mathrm{K}_{\mathrm{d}}\right)$ in equation 7 .

$$
K_{d}=\frac{C_{a q}}{C_{a d s}}
$$

Where $\mathrm{C}_{\mathrm{aq}}$ is concentration of $\mathrm{Cu}^{2+}$ in solution, $\mathrm{mg} / \mathrm{l} ; \mathrm{C}_{\mathrm{aq}}$ is concentration of $\mathrm{Cu}^{2+}$ in Double layered hydroxide in $\mathrm{mg} / \mathrm{l}$.

The isosteric heat of adsorption at constant surface coverage is calculated using the Clausius-Clapeyron equation:

$$
\frac{d\left(I n c_{e}\right)}{d T}=-\frac{\Delta \mathrm{H}_{\mathrm{x}}}{\mathrm{RT}^{2}}
$$

where, $\mathrm{Ce}$ is the equilibrium adsorbate concentration in the solution (mg.L-1), $\Delta \mathrm{Hx}$ is the isosteric heat of adsorption ( $\mathrm{kJ}$ mol-1), $\mathrm{R}$ is the ideal gas constant (8.314 J.mol-1K-1), and $\mathrm{T}$ is temperature $(\mathrm{K})$. Integrating the above equation, assuming that the isosteric heat of adsorption is temperature independent, gives the following equation:

$$
\operatorname{Inc} c_{e}=-\left[\frac{\Delta H_{\chi}}{R}\right] \frac{1}{T}+K
$$

where $\mathrm{K}$ is a constant.

The isosteric heat of adsorption is calculated from the slope of the plot of $\ln$ Ce versus 1/T different amounts of adsorbate onto adsorbent.

The linear form of the modified Arrhenius expression was applied to the experimental data to evaluate the activation energy $\left(E_{a}\right)$ and sticking probability $S^{*}$ as shown in equation 10 .

$$
\operatorname{In}(1-\theta)=S^{*}+\frac{E_{a}}{R T}
$$


The apparent Gibbs free energy of sorption $\Delta \mathrm{G}^{0}$ which is a fundamental criterion for spontaneity, was evaluated using the following equation

$$
\Delta G^{o}=R \operatorname{RIn} K_{d}
$$

$\mathrm{K}_{\mathrm{d}}$ is obtained from equation (Eq. 7).

The experimental data was further subjected to thermodynamic treatment in order to evaluate the apparent enthalpy $\left(\Delta \mathrm{H}^{\circ}\right)$ and entropy $\left(\Delta \mathrm{S}^{\circ}\right)$ of sorption using equation 12 .

$$
\Delta G^{o}=\Delta H^{o}-T \Delta S^{o}
$$

The expression relating the number of hopping (n) and that of the surface coverage $(\theta)$ as shown in equation 13 was applied to the experimental data.

$$
n=\frac{1}{(1-\theta) \theta}
$$

\section{Results and Discussions}

\subsection{SEM/EDS}

Scanning electron microscope (SEM) and Energy dispersive spectroscope (EDS) images of as-synthesized layered double hydroxides are presented in figure $1 \& 2$.

The images shows the surface morphology of the layered double hydroxides before and after adsorption studies were carried out. SEM image before adsorption studies, figure 1(a), show a rough surface with several pores while the image after adsorption studies, figure 1(b), show a smooth surface with several agglomeration of reacted hydroxide line. The smooth surface observed could be due to adsorbed metal ions filling the pores that existed before adsorption studies. The energy dispersive spectrograph before adsorption studies, figure 2(a), show the presence of metal ions used in the synthesis of the layered double hydroxides such as aluminium, sodium, and nickel and their percentage compositions. After adsorption studies, figure 2(b), the energy dispersive spectrograph, show the presence of lead ions adsorbed by the layered double hydroxide. The EDS also show that a chemical change has taken place during adsorption studies as observed in the elemental composition presented.
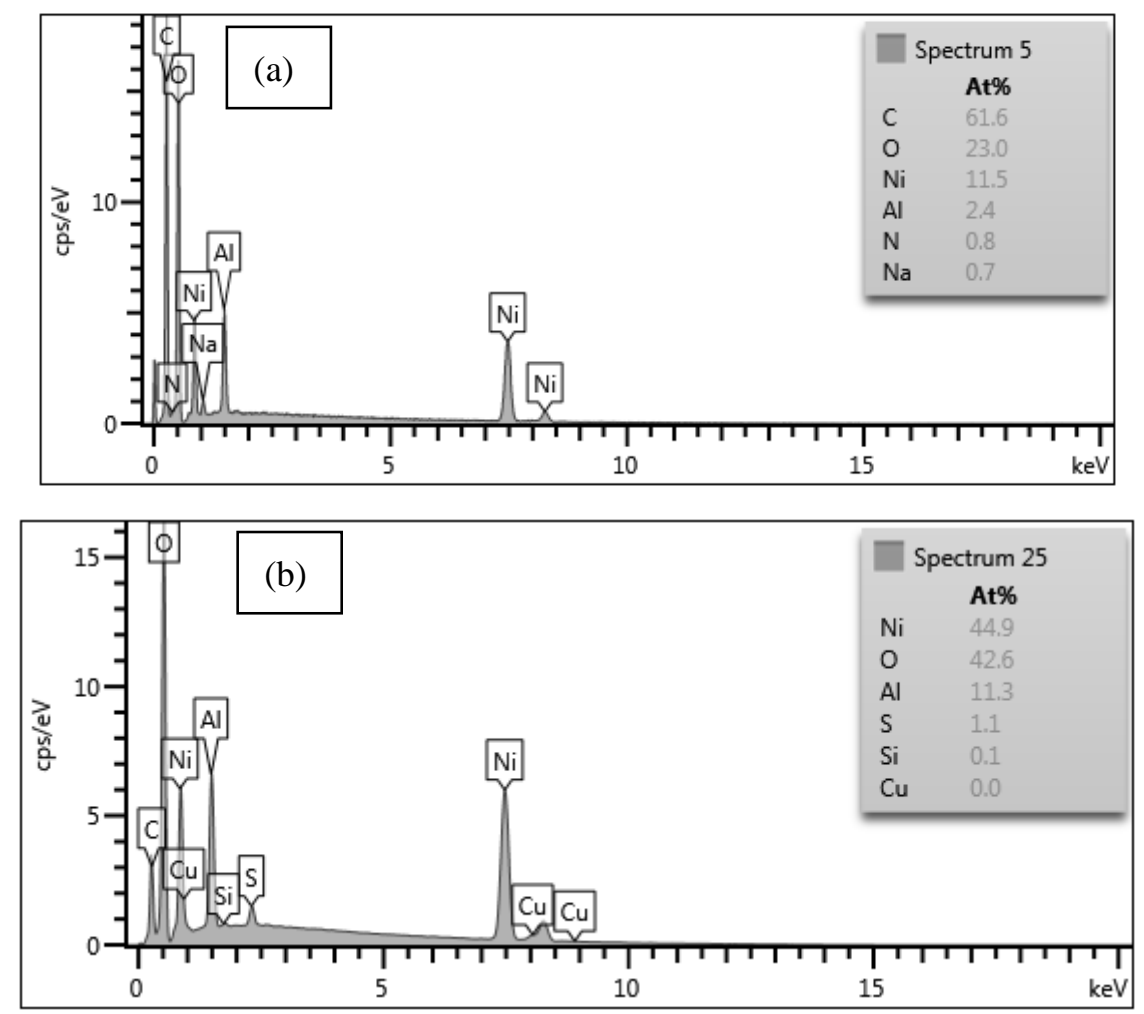

Figure 1. Energy Dispersive Spectroscopy patterns of Ni/Al- $-\mathrm{CO}_{3}$ pre \& post adsorption Energy Dispersive Spectroscopy, before (a) and after (b) adsorption studies. 

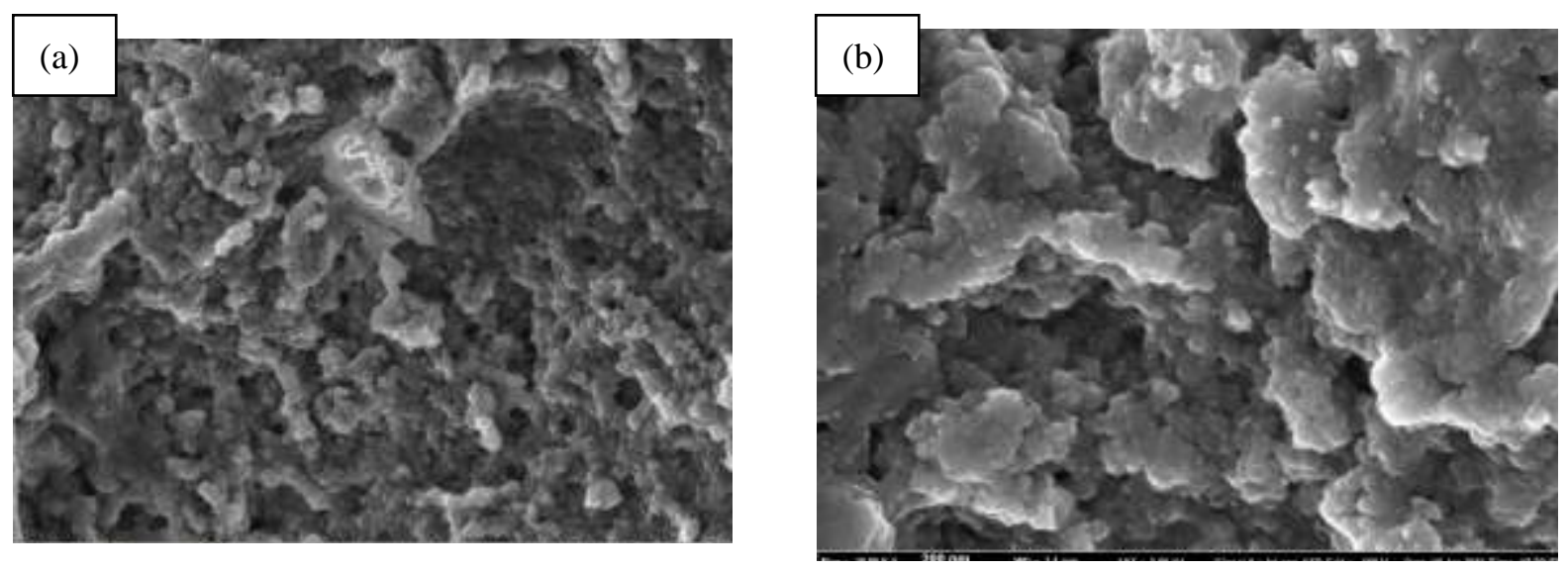

Figure 2. Scanning Electron Microscope (SEM) micrograph of Ni/Al- $\mathrm{CO}_{3}$ before (a) and after (b) adsorption studies.

\subsection{FT-IR}

The functional groups, types of bonding and identify components in the samples were determined by a Perkin Elmer Spectrum 1000 series Spectrophotometer equipped with attenuated total reflectance (ATR). The infrared spectra of the samples were recorded in the range of frequency of $400-4,000 \mathrm{~cm}^{-1}$.

Figure 3 shows the FT-IR spectra and peak numbers of the Ni/Al-LHD. The strong bond around $3400 \mathrm{~cm}^{-1}$ is associated with the stretching vibration of $\mathrm{OH}$ groups in the brucite like layer and interlayer inter molecules.

The broadening of the bond was attributed to the hydrogen-bond formation. Less intense absorption bond around $1650-1500 \mathrm{~cm}^{-1}$ was assigned to the bending vibration of the interlayer water molecules.

The carbonate ion peak is around $1400 \mathrm{~cm}^{-1}$ which is consistent with layered double hydroxides.

The low wave number region of $<1000 \mathrm{~cm}^{-1}$, the lattice vibration modes of the layered double hydroxides sheets such as M-O is assigned between $840-550 \mathrm{~cm}^{-1}$.

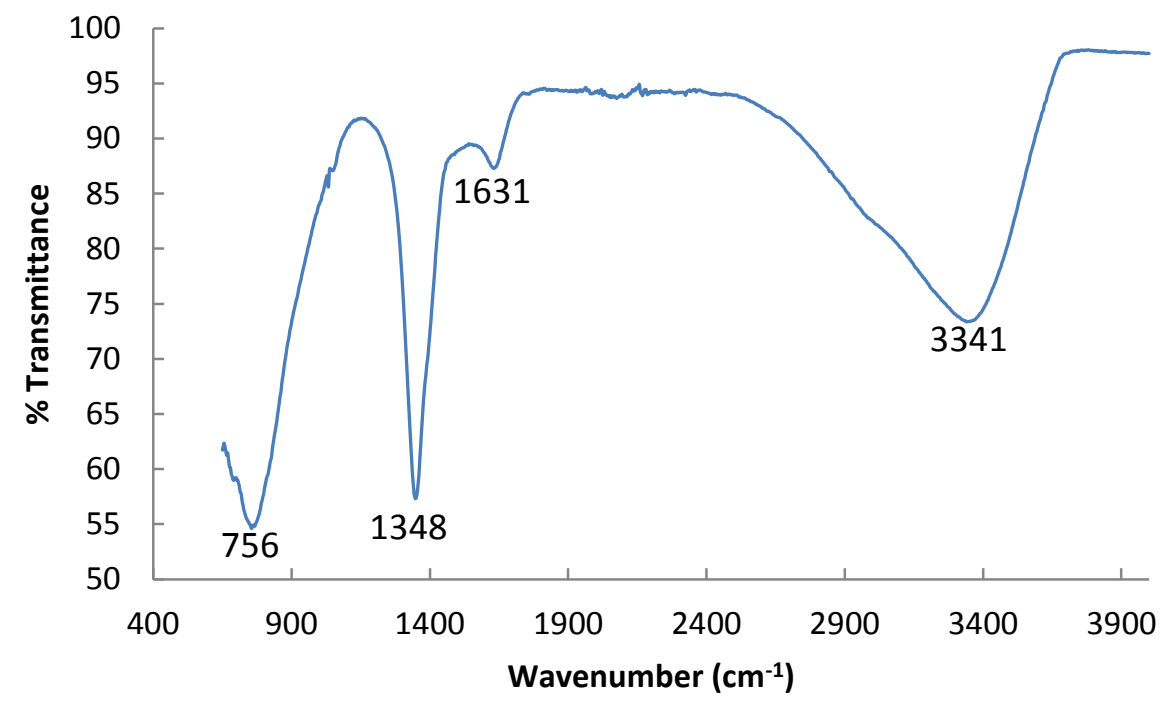

Figure 3. Ni/Al- $\mathrm{CO}_{3}$ Fourier transform infrared spectroscopy

3.2 XRD

A Shimadzu XRD 6000 Diffractometer with nickel filtered $\mathrm{Cu}-\mathrm{K} \alpha(\lambda=0.1542 \mathrm{~nm})$ beam operated at $30 \mathrm{kV}$ and $30 \mathrm{~mA}$ was used to determine the interlayer d-spacing of the clay layer in the original Ni-Al LDH, modified stearate $\mathrm{Ni}-\mathrm{Al} \mathrm{LDH}$, blends and nanocomposites using Bragg's equation $\mathrm{n} \lambda=2 \mathrm{~d} \sin \theta$. Data were recorded in $2 \theta$ range of $2^{\circ}-30^{\circ}$ using the scan rate of $2^{\circ} / \mathrm{min}$. 
Figure 4 shows the XRD patterns of the Ni/Al. The basal reflections are observed at low $2 \theta$ values and weaker non-basal reflections at higher $2 \theta$. The reflections in the $\mathrm{Ni}-\mathrm{Al}$ based layered double hydroxide is indexed to rhombohedral symmetry (space group R-3m). We observe two successive reflections at $7.58 \AA$ and $3.8 \AA$ respectively, which could be indexed to (003) and (006) planes. The lattice parameters $(\mathrm{a}=3.06 \AA$, $\mathrm{c}=7.58 \AA$ ) could be indexed to (001) and (hk0) reflections. The reflection in the mid-2 $\theta$ region of the PXRD pattern can be indexed to h01/0kl reflections and are used to determine the specific stacking sequence of layers with respect to each other.

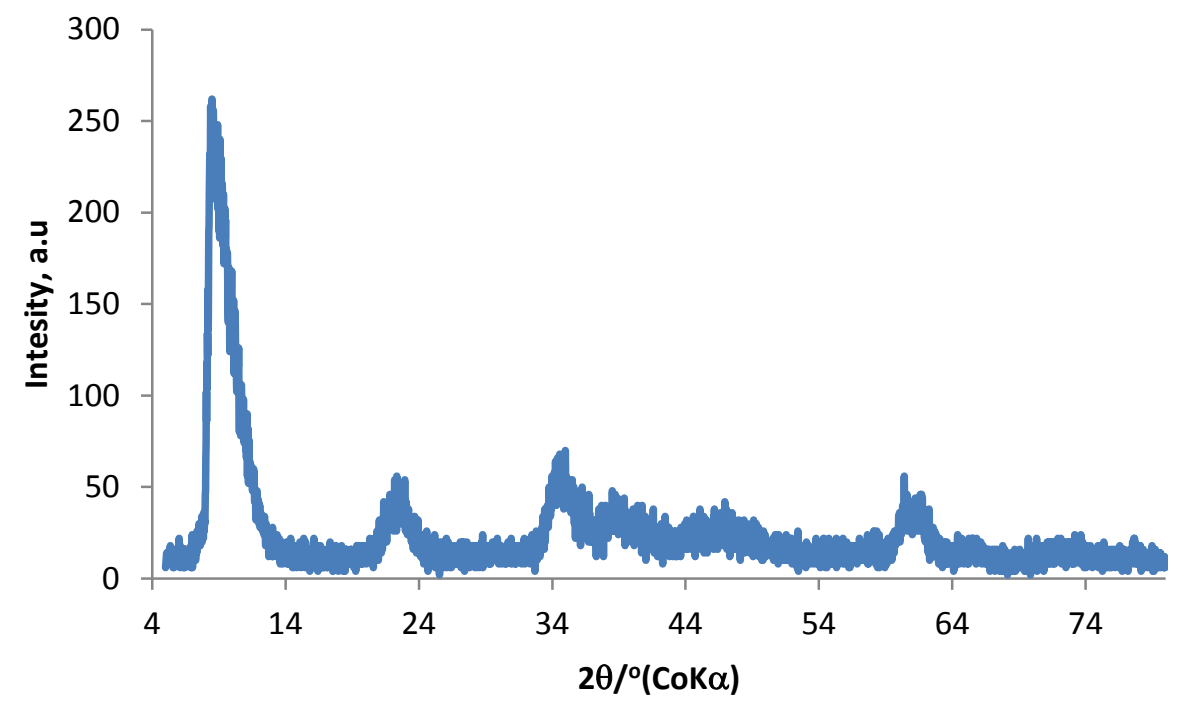

\subsection{Effect of Concentration}

Figure 4. Ni/Al- $\mathrm{CO}_{3} \mathrm{X}$-ray powder diffraction

Removal efficiency of copper ions by the adsorbents is illustrated in Figure 5. It shows that removal efficiency decreased with increasing of initial concentrations $(58.8 \%, 55.5 \%$ and $52.5 \%)$ respectively, this is probably due to rapid adsorption at all available site and the relatively small amount of adsorbent that was used, an increase in the amount of adsorbent may therefore reverse adsorption trend.

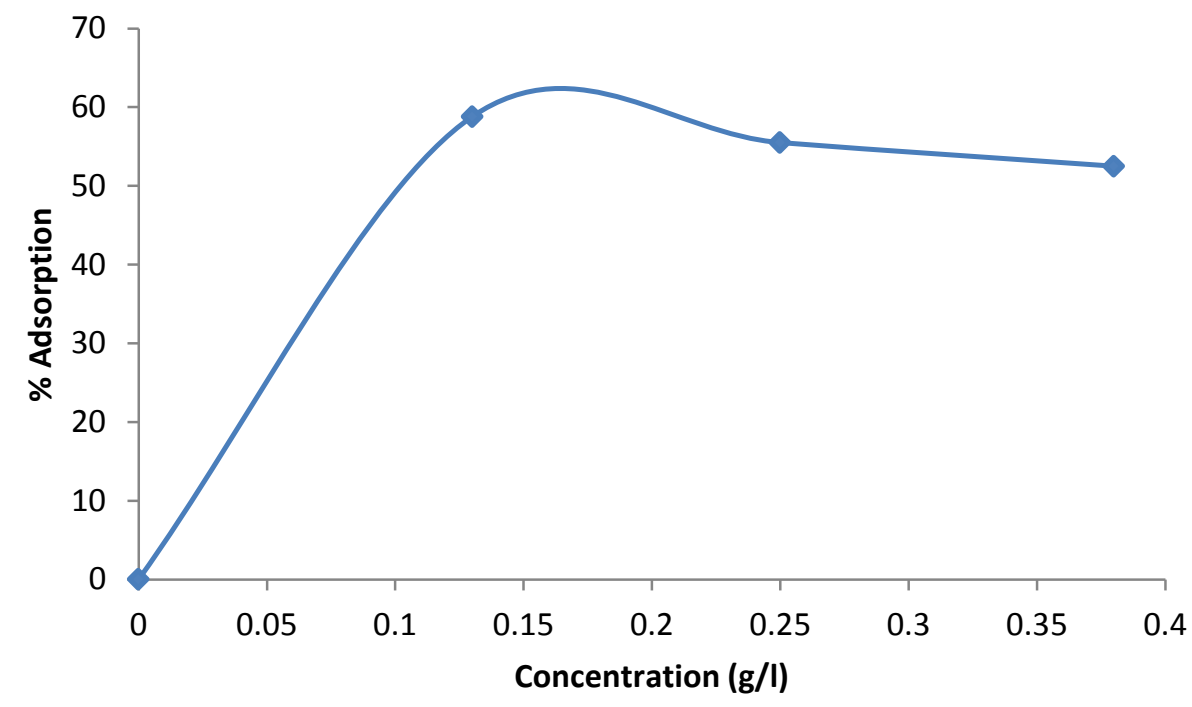

Figure 5. Effect of Concentration on adsorption of $\mathrm{Cu}^{2+}$ onto layered double hydroxide

\subsection{Isotherm Analysis}

To investigate an interaction of adsorbate molecules and adsorbent surface, two well-known models, the Langmuir and Freundlich isotherms, were selected to explicate LDH interaction in this study. 
The Langmuir plot in figure 6 fitted the experimental data with $R^{2}=0.9996$ and therefore, confirm monolayer coverage.

The influence of isotherm shape on whether adsorption is favourable or unfavourable has been considered. For a Langmuir type adsorption process, the isotherm shape can be classified by a dimension less constant separation factor $\left(R_{L}\right)$, given by Eq. (4). The calculated value of $R_{L}$ from figure 6 is 0.981 , which is within the range of $0-1$, thus confirms the favourable uptake of the layered double hydroxide adsorption process. The degree of favourability is generally related to the irreversibility of the system, giving a qualitative assessment of the layered double hydroxide interactions. The degrees tended toward zero (the completely ideal irreversible case) rather than unity (which represents a completely reversible case).

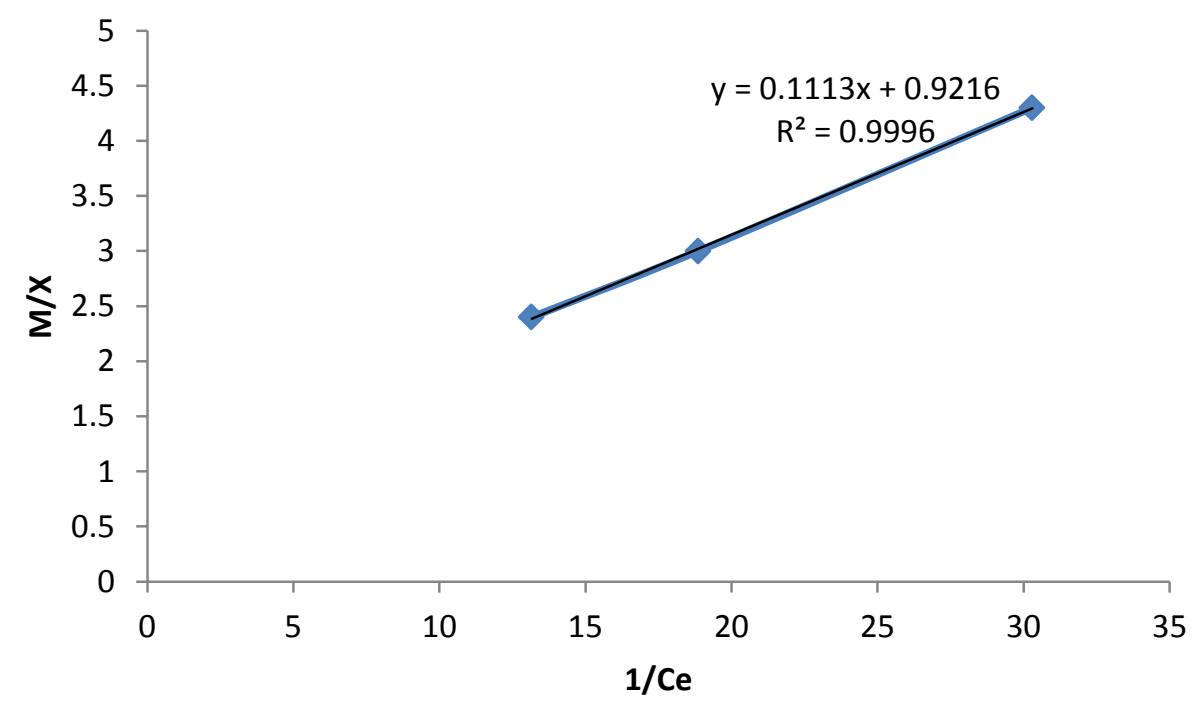

Figure 6. Langmuir Isotherm plot for adsorption of $\mathrm{Cu}^{2+}$ on layered double hydroxide

The adsorption capacity of the layered double hydroxide was extrapolated from the slope of the plot of Freundlich to be 1 in figure 7 .

The fraction of the layered double hydroxide surface covered by the $\mathrm{Cu}^{2+}$ is given as 0.55 (table 1). This value indicates that $55 \%$ of the pore spaces of the Layered double hydroxide surface were covered by the $\mathrm{Cu}^{2+}$, which means high degree of adsorption.

The effectiveness of layered double hydroxide which is the sorption coefficient of adsorbent was determined from equation 7 to be 0.54 .

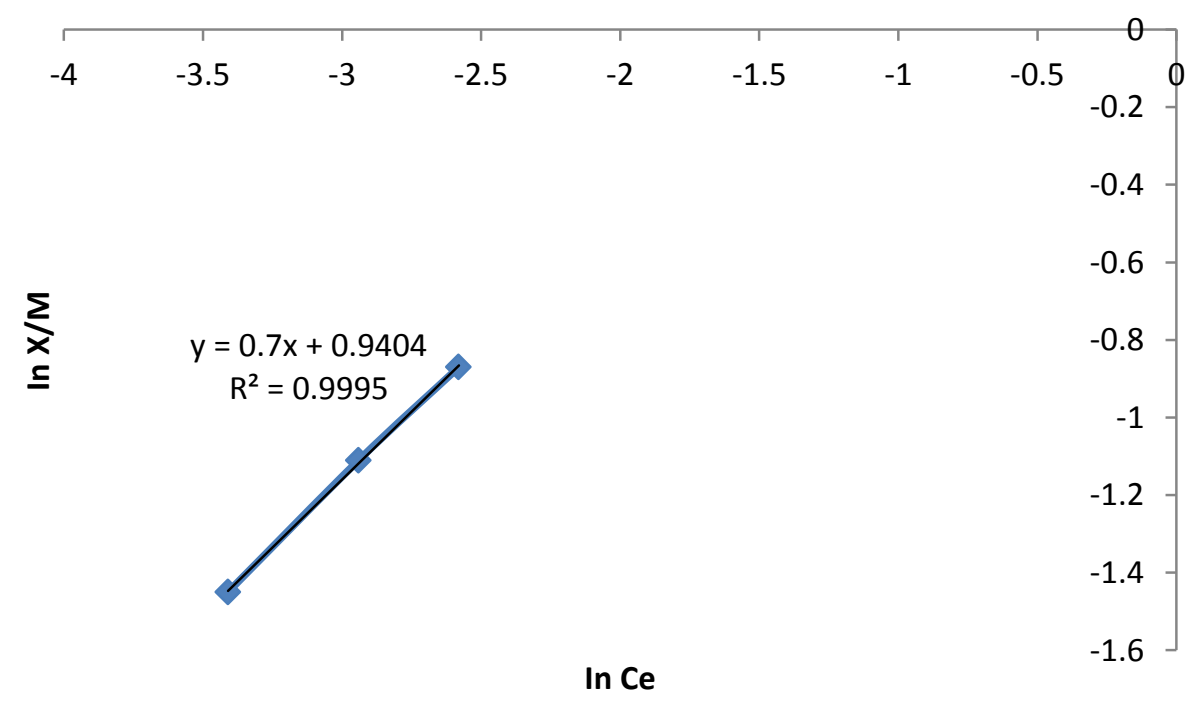

Figure 7. Freundlich Isotherm plot for adsorption of $\mathrm{Cu}^{2+}$ on layered double hydroxide 


\subsection{Effect of Temperature}

As shown in figure 8 adsorption was highest at $313 \mathrm{~K}(46.3 \%)$, and decreased slightly to $333 \mathrm{~K}(42.5 \%)$ and $353 \mathrm{~K}$ (38.8\%). This implies rapid adsorption at the lowest temperature. This could be attributed to the amount of adsorbent used for the adsorption process.

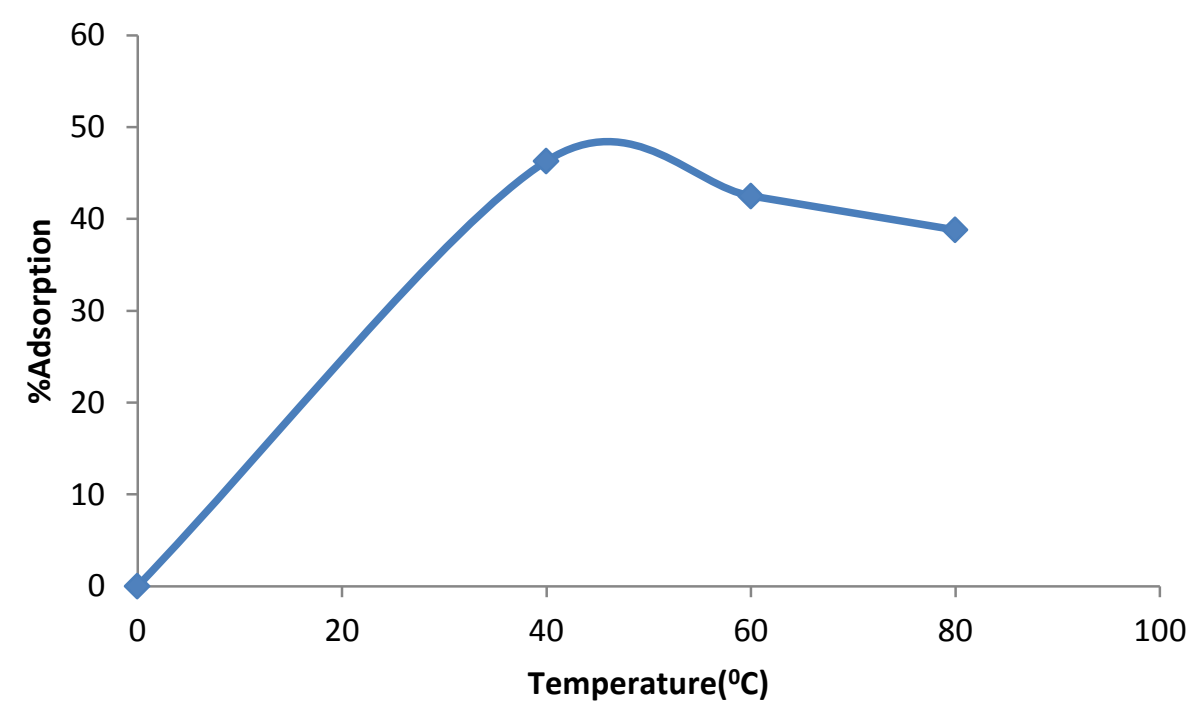

Figure 8. Effect of Temperature on adsorption of $\mathrm{Cu}^{2+}$ onto layered double hydroxide

Isosteric heat of adsorption $\Delta \mathrm{H}_{\mathrm{x}}$ is one of the basic requirements for the characterization and optimization of an adsorption process and is a critical design variable in estimating the performance of an adsorptive separation process. It also gives some indication about the surface energetic heterogeneity. Knowledge of the heats of sorption is very important for equipment and process design. A plot of $\mathrm{InC}_{\mathrm{e}}$ against $1 / \mathrm{T}$ in figure 9 gives a slope equal to $\Delta \mathrm{H}_{\mathrm{x}}$. The value of $\Delta \mathrm{H}_{\mathrm{x}}$ derived from equation 11 was $18.1 \mathrm{KJ} / \mathrm{mol}$ which indicates that adsorption mechanism was physical adsorption and in an heterogeneous surface.

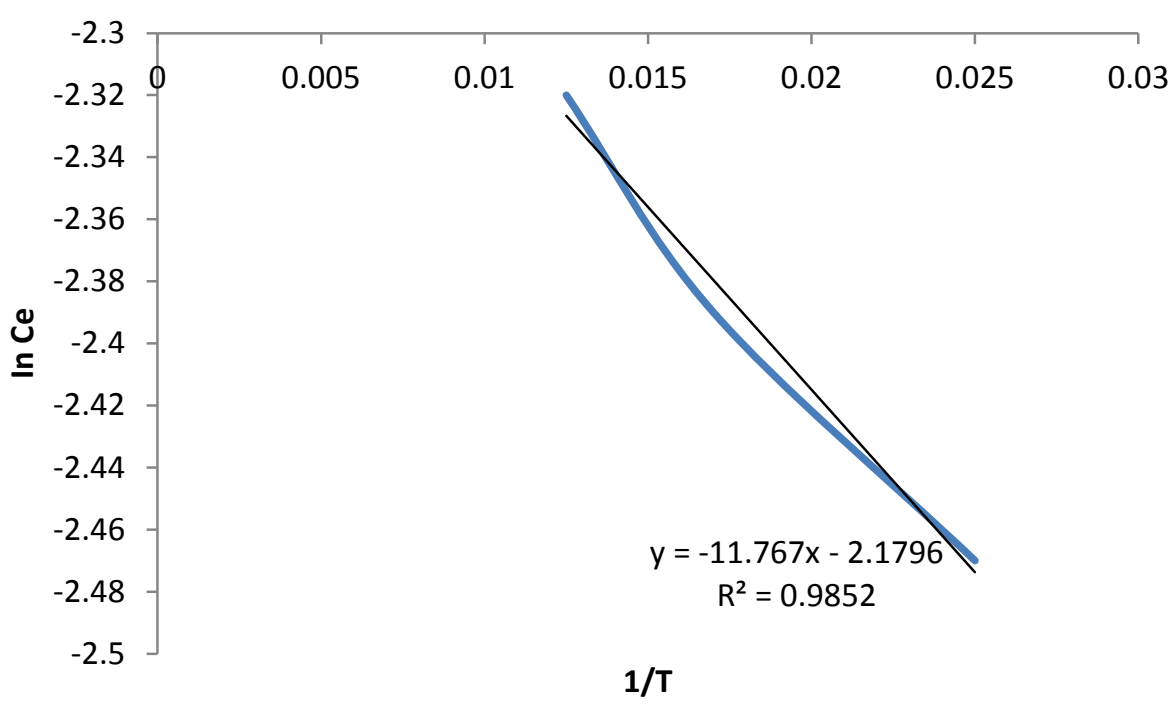

Figure 9. Plot of $\mathrm{InC}_{\mathrm{e}}$ vs. 1/T for the adsorption of $\mathrm{Cu}^{2+}$ onto layered double hydroxide

The activation energy $E_{a}$ and the sticking probability $S^{*}$ were calculated from equation 10 , the value shown in table 1 for $E_{a}$ and $S^{*}$ are $1.447 \mathrm{KJ} / \mathrm{mol}$ and 0.40 respectively, as shown in the plot in figure 10 . The value of activation energy shows that the sorption process was a physical one less than $4.2 \mathrm{KJ} / \mathrm{mol}$. The sticking probability $\mathrm{S}^{*}$ indicates the measure of the potential of an adsorbate to remain on the adsorbent. It is often interpreted as $S^{*}>1$ (no sorption), $S^{*}=1$ (mixture of physic-sorption and chemisorption), $S^{*}=0$ (indefinite sticking - chemisorption), $0<\mathrm{S} *<1$ (favourable sticking - physic- sorption). 


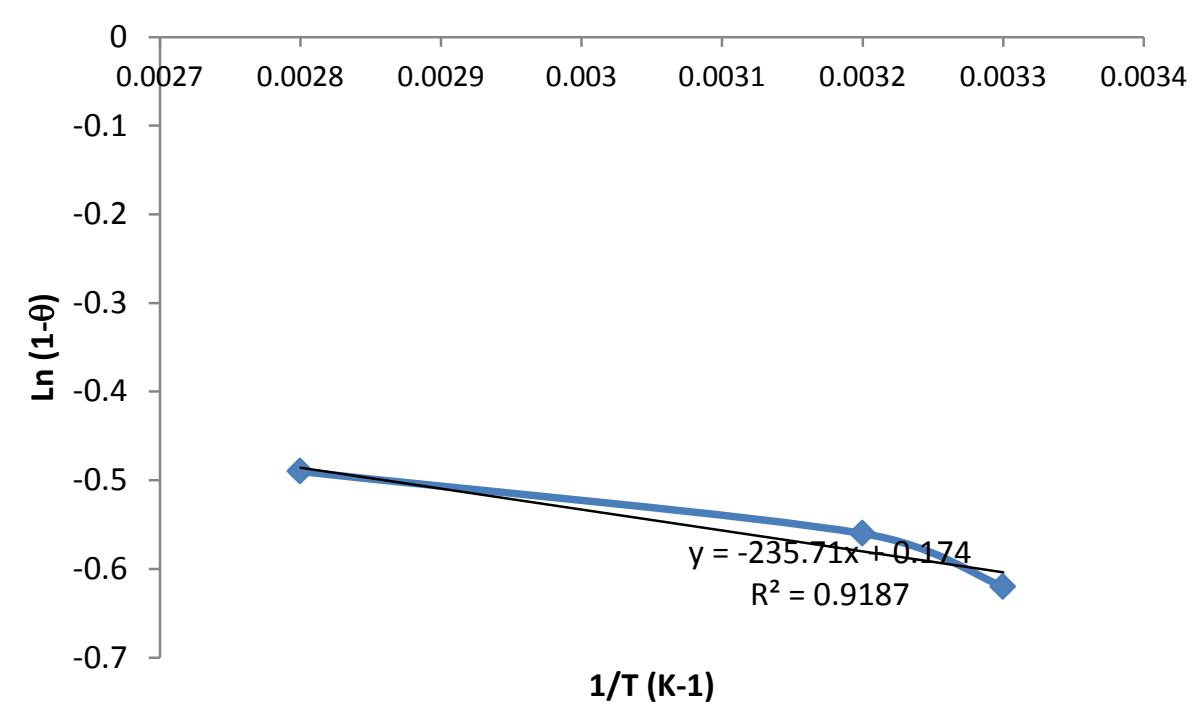

Figure 10. Plot of $\operatorname{In}(1-\theta)$ vs. $1 / \mathrm{T}\left(\mathrm{K}^{-1}\right)$ for the adsorption of $\mathrm{Cu}^{2+}$ onto layered double hydroxide

The values of the enthalpy change $\left(\Delta \mathrm{H}^{\circ}\right)$ and entropy change $\Delta \mathrm{S}^{\circ}$ were calculated from equation 10 to be $-7.135 \mathrm{~J} / \mathrm{mol}$ and $24 \mathrm{~J} / \mathrm{molK}$ respectively, as shown in figure 11 . A negative $\Delta \mathrm{H}^{\circ}$ suggests that sorption proceeded favourably at a lower temperature and the sorption mechanism was exothermic. A positive value of $\Delta \mathrm{S}^{0}$ $(24 \mathrm{~J} / \mathrm{molK})$ reflects the affinity of the adsorbent towards the adsorbate species. In addition, positive value of $\Delta \mathrm{S}^{0}$ suggests increased randomness at the solid/solution interface with some structural changes in the adsorbate and the adsorbent. The adsorbed solvent molecules, which are displaced by the adsorbate species, gain more translational entropy than is lost by the adsorbate ions/molecules, thus allowing for the prevalence of randomness in the system. The positive $\Delta \mathrm{S}^{0}$ value also corresponds to an increase in the degree of freedom of the adsorbed species.

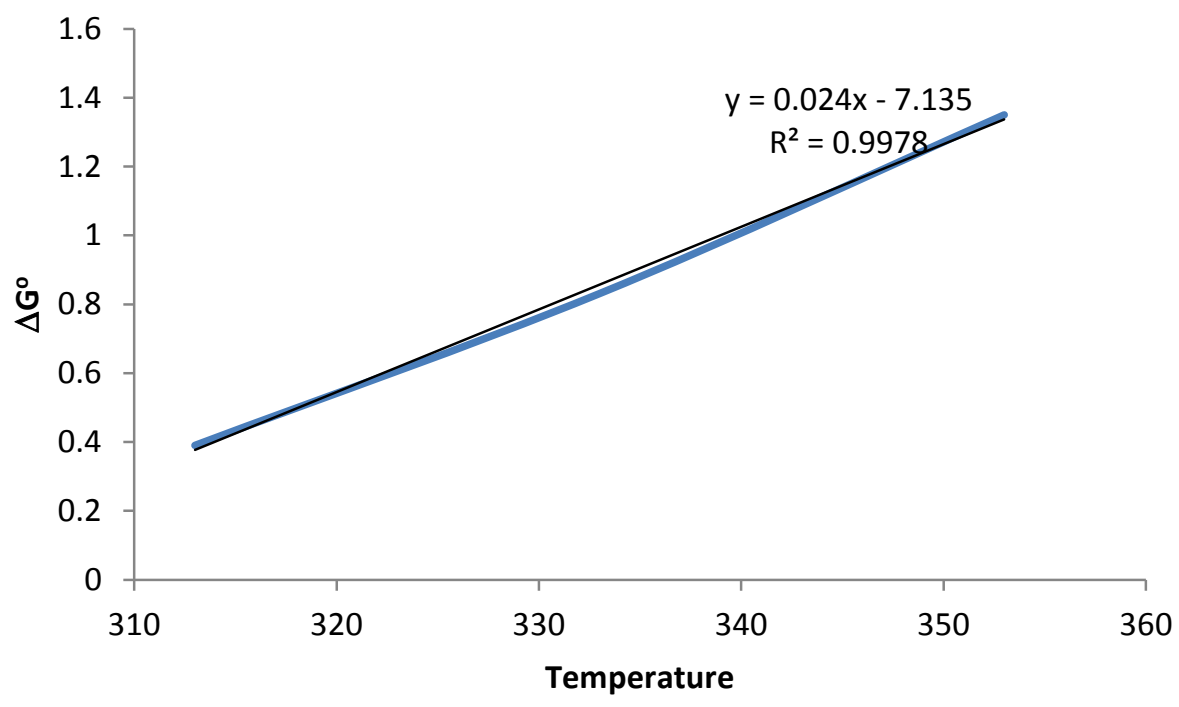

Figure 11. Plot of $\Delta \mathrm{G}^{\mathrm{o}}$ vs. Temperature for the adsorption of $\mathrm{Cu}^{2+}$ onto layered double hydroxide

The probability of $\mathrm{Cu}^{2+}$ finding vacant site on the surface of the layered double hydroxide during the sorption was correlated by the number of hopping (n) done by the $\mathrm{Cu}^{2+}$. The hopping number presented in table 1 is 4 . The lower the hopping number, the faster the adsorption. 
Table 1. Equilibrium and Thermodynamic Parameters

\begin{tabular}{ccccccccc}
\hline $\begin{array}{c}\text { Isosteric heat } \\
\text { of adsorption }\end{array}$ & $\begin{array}{c}\text { Sticking } \\
\text { Probability }\end{array}$ & $\begin{array}{c}\text { Activation } \\
\text { energy }\end{array}$ & $\begin{array}{c}\text { Apparent } \\
\text { entropy }\end{array}$ & $\begin{array}{c}\text { Apparent } \\
\text { enthalpy }\end{array}$ & $\begin{array}{c}\text { Surface } \\
\text { coverage }\end{array}$ & $\begin{array}{c}\text { Separation } \\
\text { factor }\end{array}$ & $\begin{array}{c}\text { Hoping } \\
\text { number }\end{array}$ & $\begin{array}{c}\text { Sorption } \\
\text { coefficient }\end{array}$ \\
$\begin{array}{c}\Delta \mathrm{H}_{\mathrm{x}} \\
\mathrm{KJ} / \mathrm{mol}\end{array}$ & $\mathrm{S} *$ & $\begin{array}{c}\mathrm{E}_{\mathrm{a}} \\
\mathrm{KJ} / \mathrm{mol}\end{array}$ & $\begin{array}{c}\Delta \mathrm{S}^{\mathrm{O}} \\
\mathrm{J} / \mathrm{molK}\end{array}$ & $\begin{array}{c}\Delta \mathrm{H}^{\mathrm{O}} \\
\mathrm{J} / \mathrm{mol}\end{array}$ & $\theta$ & $\mathrm{S}_{\mathrm{f}}$ & $\mathrm{N}$ & $\mathrm{K}_{\mathrm{d}}$ \\
\hline 18.1 & 0.4 & 1.447 & 24 & -7.135 & 0.55 & 0.974 & 4 & 0.54 \\
\hline
\end{tabular}

\section{Conclusion}

In this study layered double hydroxide was used to recover copper $\left(\mathrm{Cu}^{2+}\right)$ ions from aqueous solutions. The results indicate that removal of copper $\left(\mathrm{Cu}^{2+}\right)$ strongly dependent on contact time. Increasing temperature and concentration does not have favourable effect on the adsorption capacity of layered double hydroxide. The equilibrium data were described well by a Langmuir isotherm and Freundlich isotherm indicating that the adsorption of copper on layered double hydroxide was as a monolayer. The study of thermodynamic properties indicate a spontaneous adsorption process. The efficiency of the LDH could be enhanced by increasing its amount considerably.

\section{References}

Chen, D. Z., Zhang, J. X., \& Chen, J. M. (2010). Adsorption of methyl tert-butyl ether using granular activated carbon: Equilibrium and Kinetic analysis. Int.J. Environ. Sci Tech., 7(2), 235-242.

Cavani, F., Trifir`o, F., \& Vaccari, A. (1991). Hydrotalcite-type anionic clays: preparation, properties and applications. CatalysisToday, 11(2), 173-301.

Pshinko, G. N. (2013). Layered double Hydroxide as Effective Adsorptions for U(vi) and Toxic Heavy Metal Removal for Aqueous Media. Journal of Chemistry, Article ID 347178, 9.

Gong, J., Liu, T., Wang, X., Hu, X., \& Zhang, L. (2001). Efficient Removal of Heavy Metal ions from Aqueous Systems with the assembly of Anisotropic Layered Double Hydroxide Nanocrystal @ Carbon Nanosphere. Environ Sci Technol., 45(14), 6181 -7.

Gupta, V. K., Rastogi, A., Saini, V. K., \& Jain, N. (2006). Biosorption of copper(II) from aqueous solution by Spirogya species. J. Colloid and Interface Science, 296(1), 59-63.

Hetterley, R. D., Mackey, R., Jones, J. T. A., Khimyak, Y. Z., Fogg A. M., \& Kozhevnikov, I. V. (2008). One-step conversion of acetone to methyl isobutyl ketone over Pd-mixed oxide catalysts prepared from novel layered double hydroxides. J. Catal., 258, 250-255.

Igwe, J. C., \& Abia, A. A. (2006). Bioseperation process for removing heavy metals from wastewater using biosorbents. African Journal of Biotechnology, 5(12), 1167-1179.

King, P., Srinivas, P., Kumar, Y. P., \& Prasad, V. S. R. K. (2006). Sorption of copper(II) ion from aqueous solution by Tecton grandis 1.f.(teak leaves powder). J. Hazard. Mater., 136(3), 560-566.

Lu, H. J., Luan, M. T., Zhang, J. L., \& Yu, Y. X. ( 2008). Study on the adsorption of Cr(VI) onto landfill liners containing granular activated carbon or bentonite activated by acid. Journal of china University of Mining \& Technology, 18(1), 125-130.

Perez, M. R., Parlovic, I., Barriga, C., Cornejo, J., Hermosin, M. C., \& Ulibarri, M. A., (2006). Uptake of $\mathrm{Cu}^{2+}$, $\mathrm{Cd}^{2+}$ and $\mathrm{Pb}^{2+}$ on $\mathrm{Zn}-\mathrm{Al}$ Layered Double Hydroxide intercalated with edta. Applied Clay Science, 32(3-4), 245-251.

Mahvi, A. H. (2008). Application of agricultural fibers in pollution removal from aqueous solution. Int.J . Environmental Science \& Technology, 5(2), 275-285.

Mohanty, K., Das, D., \& Biswas, M. N. (2006). Preparation and characterization of activated carbons from Sterculia alata Nutshell by chemical activation with zinc chloride to remove phenol from wastewater. Adsorption, 12, 119-132.

Richardson, M. C., \& Braterman, P. S. (2009). Cation exchange by anion-exchanging clays: the effects of particle aging. J. Mater. Chem., 19, 7965-7975.

Tran, H. H., Roddick, F. A., \& O’Donnell, J. A. (1999). Comparision of chromatography and desiccant silica gels for the adsorption of metal ions. I. Adsorption and kinetics. Water Research, 33, 2992-3000. 
Volesky, B. (1992). Removal of heavy metals by biosorption. In: Ladisch MR, Bose A (eds). Harnessing biotechnology for the 21stCentury. Amer. Chem. Soc., Washington DC, Pp. 462-466.

Zaini, H., Mohd, N. A. R., Yamin, Y., Siti, M. S., \& Ahmad, S. (2011). Removal of Copper from aqueous Solution by adsorption using magnesium/Aluminium hydrogenphosphate layered double hydroxides. Journal of Nuclear and Related Technologies, 8(2).

Zhang, L., Zhao, L., Yu, Y., \& Chen, C. (1998). Removal of Pb2+ from aqueous solution by non-living Rhizopus nigricans. Water Res., 32, 1437-1444.

\section{Copyrights}

Copyright for this article is retained by the author(s), with first publication rights granted to the journal.

This is an open-access article distributed under the terms and conditions of the Creative Commons Attribution license (http://creativecommons.org/licenses/by/3.0/). 